\title{
SEMBLANZA
}




\section{FRANCISCO TOMÁS Y VALIENTE (1932-1996)}

He aquí unas páginas que nunca hubiera deseado verme en la tesitura de escribir y que, sin embargo, acaecido el dramático hecho que las motiva y amistosamente requerido por nuestro Director, no puedo dejar de redactar. Lo hago, por tanto, incapaz de rechazar la petición en este sentido del Profesor Gacto Fernández, procurando atenerme a la brevedad que se me solicita.

Francisco Tomás y Valiente, Director de este Anuario, asesinado el 14 de febrero de 1996, había nacido en Valencia el 8 de diciembre de 1932. Allí cursó los estudios de la licenciatura en Derecho y fue alumno de quien entonces ocupaba la cátedra de Historia del Derecho en la Universidad valenciana, el Dr. don José María Font Rius, de quien Tomás y Valiente conservó siempre el mejor recuerdo y a quien tributó invariable afecto.

Su formación como profesor e investigador de la historia jurídica española transcurrió en los claustros valencianos y más tarde, entre 1962 y 1964, en los de la entonces única Universidad de Madrid. Dirigió su tesis doctoral sobre el proceso monitorio - por la que recibiría el Premio Extraordinario del Doctorado- el Dr. don Víctor Fairén Guillén, ilustre procesalista con vastos conocimientos del desarrollo histórico de aquella rama del Derecho. Maestros de Tomás y Valiente fueron ulterior y sucesivamente los doctores don Juan García González en Valencia y don Alfonso García-Gallo en Madrid, y junto a ambos preparó sus primeras investigaciones posteriores a la tesis doctoral, que acreditan la temprana maestría de su autor y con las que inició su colaboración en este Anuario. En efecto, el estudio sobre La prisión por deudas en los Derechos castellano y aragonés apareció en el volumen $\mathrm{XXX}$, correspondiente a 1960, y en el siguiente (XXXI) se dio cabida al trabajo sobre El perdón de la parte ofendida en el Derecho penal castellano (siglos XVI, XVII y XVIII). Poco después publicaría Tomás y Valiente su primer libro: el estudio institucional de 
Los validos de la monarquía española del siglo XVII (Madrid, 1963). Resulta oportuno recordar estas primeras publicaciones no sólo por su calidad intrínseca, sino también porque presentan algunos rasgos que luego se convertirían en otras tantas constantes del quehacer investigador de Tomás y Valiente, más dignas de mención por cuanto en aquellos años la Historıa del Derecho todavía permanecía en España recluida dentro de los límites del más estricto medievalismo mientras, por otra parte, se solía cultivar con el recurso poco menos que exclusivo a fuentes publicadas. Frente a esas pautas, Tomás y Valiente se contó entre los primeros historiadores del Derecho de nuestro país que en los años sesenta acometió decididamente el estudio de los siglos modernos, y que además lo hizo poniendo a contribución la documentación inédita conservada en los grandes archivos.

Profesor adjunto de Historia del Derecho de las universidades de Valencia, primero, y después de Madrid, Tomás y Valiente obtuvo la cátedra de la asignatura en la Universidad de La Laguna en 1964, y en los meses finales de ese año se incorporó, en virtud de concurso de traslado, a la Universidad de Salamanca, donde permanecería hasta 1980. Desde el punto de vista universitario y en lo que concierne a la Historia del Derecho, esta larga etapa salmantina constituyó el período principal y más fecundo de su vida académica.

En Salamanca se integró enseguida Tomás y Valiente en el sector de los profesores más dinámicos y con mayor vocación universitaria, que tan poderosamente contribuyeron a la profunda renovación de la Facultad de Derecho. En ella desempeñó Tomás y Valiente la tareas profesorales con entrega y aun entusiasmo ilimitados, y desplegó sus excepcionales dotes para la enseñanza, recompensado con la admiración, respeto y afecto unánimes de las sucesivas y numerosas promociones de alumnos que tuvieron la fortuna de recibir sus enseñanzas y de disfrutar de sus clases y seminarios. Tomás y Valiente tenía muy viva conciencia de la trascendencia social de la universidad y de la correlativa responsabilidad del profesor universitarı, que en su caso se materializó en el más riguroso y constante cumplimiento de los deberes académicos. Concebía la universidad como sede de la razón crítica en la que, amén de formar cuadros profesionales, era preciso, por tanto, enseñar a pensar, atender a los saberes básicos y contribuir a enriquecer el patrimonio intelectual recibido. De ahí que, sin perjuicio de su exigente dedicación a la docencia, considerase a la investigación como la tarea más genuina y, en último término, esencial de la universidad, idea, por cierto, del oficio universitario que se mantuvo inalterada hasta el final de sus dias.

Fiel a esa arraigada concepción del alma mater, en Salamanca forjó también Tomás y Valiente una obra de investigación copiosa y de reconocida calidad. Entre los títulos más tempranos hallamos algunos que derivan de las con- 
venciones académicas de la época, de la reglamentación de las oposiciones a cátedras o bien de algún encargo menos próximo a sus más hondas preocupaciones. Así, el estudio sobre La sucesión de quın muere sin parientes y sin disponer de sus bienes (en el volumen XXXVI de este Anuario), o el trabajo sobre Las fianzas en los Derechos aragonés y castellano, cuya publicación en los Recueils de la Société Jean Bodin (volumen XXIX) se demoró hasta 1971, aunque lo ultimó igualmente al poco de su llegada a Salamanca.

Mas, al establecerse en la ciudad del Tormes, traía también consigo Tomás y Valiente otros artículos recientes, proyectos y obras en curso de realización, que se deben incluir dentro de las líneas de investigación o campos temáticos a los que mayor atención prestó en los años subsiguientes.

Por lo que se refiere a la primera de esas líneas, relativa a materias de historia del Derecho penal y procesal penal, merece ser recordado, por ejemplo, el artículo sobre La última etapa y la abolición de la tortura judicial en España, testimonio de su paso por la Universidad tinerfeña, que se publicó en los Anales de la Universidad de La Laguna (Facultad de Derecho, I, 1964), así como, sobre todo, el libro sobre El Derecho penal de la Monarquía absoluta (siglos $X V I, X V I I$ y $X V I I I)$, que seguramente constituye una de sus obras más logradas y, sin duda, más representativas de sus postulados metodológicos, de su técnica de trabajo y de sus preocupaciones más profundas. Basta reparar, para convencerse de ello, en la delimitación cronológica de la materia, en la elección de las fuentes empleadas y en el enfoque que impregna las páginas de $E l$ Derecho penal ., que es, ciertamente, el estudio de un modernista que teje su relato con fibras provenientes de los textos legales, de la doctrina de juristas y teólogos y de los procesos penales conservados en los legajos de los archivos. Y es que a su autor no le satisfacía la mera recomposición de la textura jurídico-formal del Derecho punitivo del absolutismo, sino que aspiraba a trascender esa óptica, a dar también cuenta de la paralela práctica penal y a mostrar la función desempeñada por los instrumentos penales en el entramado político y social de la época.

Para Tomás y Valiente, la investigación ius-histórica no constituía, por lo demás, una actividad ajena y desconectada de sus inquietudes cívicas y de sus preocupaciones vitales. Partidario de la incondicional sujeción a las exigencias eruditas y al método histórico-crítico, que observó sin excepción, era, sin embargo, la antítesis del intelectual indiferente a las situaciones de su entorno social y político. Poco antes de su muerte confesaba que había sido siempre lector acostumbrado a relacionar lo que leía con los problemas de la convivencia. Me permitiría añadir que a relacionar no sólo lo que leía sino también lo que escribía. De ahí que su atracción por la historia del Derecho penal y procesal penal no surgiera por puro azar. El estudioso del ordenamiento criminal del 
Antiguo Régimen, el autor de los trabajos que en 1973 reunió en el volumen $L a$ tortura en España, el traductor y comentarista de Beccaria, era un ciudadano de la España de su tiempo preocupado por el hombre real y concreto, inquieto por la vulneración de los derechos humanos, insobornable luchador en favor de dichos derechos, persuadido, en suma, de que, como escribió en 1971, «la más alta misión del Derecho y del jursta (es) la de defender jurídica y eficazmente el máximo respeto posible para los derechos del hombre». De espíritu abierto y tolerante, fue siempre defensor intransigente y sin contemplaciones de los derechos humanos.

La segunda línea de investigación iniciada tempranamente y en la que Tomás y Valiente perseveró en los años a que ahora me refiero tuvo por objeto la organización política e institucional de los siglos modernos. Organización castellana (y, en su caso, hispánica), preciso, porque Tomás y Valiente, salvo en las ocasiones que han quedado registradas de atención al Derecho aragonés o, más adelante, alguna incursión aislada en el Derecho valenciano, fue esencial y casi exclusivamente historiador del Derecho castellano, bien considerado en sí mismo bien en su ulterior y genérica proyección hispánica.

Resulta imposible hacer aquí mención pormenorizada de los numerosos trabajos que Tomás y Valiente realızó en este orden de cosas. Entre su amplia producción, y como muestra sólo ejemplificadora, me limitaré a recordar los estudios reunidos en el volumen Gobierno e instituciones en la España del Antiguo Régımen (Madrid, 1982), que contiene, entre otras, las páginas sobre La Diputación de las Cortes de Castilla (1525-1601) (las más antiguas de cuantas se recogen en el libro citado, publicadas inicialmente en este Anuario, XXXII, 1962). Es igualmente inexcusable la mención del conjunto de trabajos dedicados por Tomás y Valiente a las ventas de oficios, tema que proyectaba desarrollar en una amplia monografía y que, entre tanto, esclareció en múltiples artículos sobre aspectos parciales, alguno de los cuales recibió un tratamiento tan extenso que ocupó por sí solo un libro entero (La venta de oficios en Indias (1492-1606) (Madrid, 1972).

Considero ineludible recordar, en tercer lugar, la contribución de Tomás y Valiente al tomo vigésimo quinto de la Historıa de España fundada por Menéndez Pidal y dirigida en la actualidad por Jover, para el que redactó el Prólogo y la parte titulada El Estado del siglo XVII: el gobierno de la Monarquía y la administración de los reınos (Madrid, 1982). Ya el título implicaba por sí solo una toma de posición conceptual contundente. Para Tomás y Valiente, las circunstancias bajomedievales desembocaron durante el reinado de los Reyes Católicos en «la aparición de un verdadero Estado», cuyos fundamentos y caracteres analiza antes de pasar a describir el aparato institucional de la monarquía y de los reinos en particular. Con carácter previo, en el Prólogo, 
había examinado la significación en el lenguaje de la época de las nociones de patria y de nación, y había sentado la afirmación de que «el problema principal de España en el siglo XVI (fue) el constitucional».

Por debajo de los centenares de páginas dedicadas al estudio de la organización política e institucional moderna latían también, como en Tomás y Valiente resultaba habitual, sus preocupaciones más profundas y su concepción de la Historia, según la cual esta debía ayudar «a entender el tiempo que el historiador y sus lectores viven, la sociedad en que conviven». De lo que en esta ocasión se trataba era, por consiguiente, de progresar en la comprensión de los problemas derivados de la articulación estatal del poder político, y ello mediante el conocimiento previo de su génesis y de su despliegue en los siglos modernos. Preocupación, pues, por el Estado, «casi obsesiva», como reconocería más adelante. Mas no por cualquier Estado, y menos aún por el Estado en abstracto, sino precisamente por el proceso de conformación política de esa realidad a la que llamamos España. He ahí otro de los asuntos que apasionaron a Tomás y Valiente a lo largo de su vida y que le produjeron creciente inquietud: el relativo al proceso de formación histórica de España, sus particularidades y sus derivaciones.

La tercera línea de trabajo que Tomás y Valiente abrió en la etapa salmantina supuso la incursión decidida en el Derecho e instituciones surgidas de la revolución liberal, en las que, salvo en ocasiones muy contadas, los historiadores juristas todavía no habían osado penetrar. En aquellos años acaso nadie se esforzó en España como él por ampliar al máximo el ámbito cronológico de los estudios histórico-jurídicos, y en concreto por incorporar a nuestra disciplina la consideración del antaño denostado ciclo liberal. Dentro de esta vertiente destaca el libro sobre El marco políttco de la desamortización en España (Barcelona, 1971), así como el rosario de publicaciones sobre ese tema que siguieron a la aparición de dicho volumen. Al período salmantino se remontan, igualmente, el interés de Tomás y Valiente por la historia del constitucionalismo español y sus primeros artículos sobre esta materia. Recuérdense las Notas para una nueva Historia del constitucionalismo español (en Sistema, 17-18, 1977) y las páginas sobre La Constitución de 1978 y la historia del constitucionalismo español (en este Anuario, L, 1980), estudios ambos claramente relacionados y aun complementarios en los que anticipó, de una parte, sus presupuestos metodológicos, y de otra un esquema interpretativo muy personal de la trayectoria constitucional española.

De sus últimos años en el Estudıo salmanticense procede, en fin, el Manual de Historia del Derecho español (Madrid, 1979), que encierra la expresión más neta de su visión de la evolución jurídica hispánica y se alza como la síntesis y remate de su etapa más fecunda para la Historia del Derecho. En el Manual 
puso Tomás y Valiente a prueba las posiciones que tres años antes había expuesto en Historia del Derecho e Historia (en el volumen colectivo Once ensayos sobre la Historia, Madrid, 1976) y que impregnan su concepción de la Historia del Derecho: su convicción de que las normas no agotan la realidad jurídica; su insatisfacción ante el formalismo jurídico en cualquiera de sus manifestaciones; su convencimiento de que el Derecho «goza sólo de muy relativa autonomía» y de que, por eso mismo, es preciso contemplarlo también en sus conexiones con los restantes sectores de la realidad social; su consideración de la Historia del Derecho como ciencia histórica, como «especialidad de la Historia».

Así pues, al finalizar la década de los setenta era Tomás y Valiente un historiador del Derecho en plena madurez. Profesor prestigioso e investigador solvente con amplia obra en su haber; estudioso de fuerte personalidad, con preocupaciones definidas e ideas propias acerca del estatuto conceptual y metodológico de la Historia jurídica y del modo de cultivarla. No es extraño que en el transcurso de los años se hubieran ido agrupando a su alrededor jóvenes licenciados o ex alumnos sobre los que ejerció su ejemplar magisterio y que, agradecidos, se siguen proclamando con orgullo discípulos suyos.

En ese momento de plenitud académica se cruzó en su vida en 1980 el nombramiento de magistrado del Tribunal Constitucional, en el que permanecería doce años. Poco después se produjo también su desvınculación admınistrativa de la Universidad de Salamanca, al convertirse en virtud de concurso de traslado en catedrático de la Universidad Autónoma de Madrid. En una síntesis tan apretada como la presente de su trayectoria en tanto que historiador del Derecho, escaso lugar merecería el recuerdo de esta etapa de magistrado (entre 1980 y 1986) y luego Presidente del Tribunal Constitucional (desde 1986 hasta 1992) si en su transcurso se hubiera desentendido Tomás y Valiente por completo de la universidad y de la Historia del Derecho. Sin embargo, lo cierto es que, por el contrario, aun en situación de excedencia y apartado de la docencia ordinaria, ni se ausentó enteramente del ámbito académico ni olvidó su condición de historiador del Derecho. Recargado de trabajo en el Trbunal Constitucional, todavía encontró tiempo, no obstante, para impartir cursos extraordinarios, redoblar su actividad de conferenciante, participar en algunos congresos, proyectar su magisterio sobre nuevos discípulos, ahora en la Universidad Autónoma.

En 1981 se hizo cargo de la dirección de la colección de «Clásicos del constitucionalismo español», editada por el Centro de Estudios Constitucionales, y en 1989 fue elegido académico de número de la Real Academia de la Historia. Su desbordante vitalidad y su inmensa capacidad de trabajo le permitieron mantenerse al día en el conocimiento de las novedades bibliográficas y continuar escribiendo numerosos estudıos de temática hıstórico-jurídica, al margen 
y con independencia de los referidos a la justicia constitucional. Entre aquellos predominan los dedicados a la historia jurídica reciente, esto es, a los siglos XIX y xx, como el libro sobre Martínez Marina historiador del Derecho (Madrid, 1991) (versión ampliada de su discurso de ingreso en la Real Academia de la Historia), o los trabajos sobre otros tantos aspectos de la codificación y del constitucionalismo hispánico decimonónico, reunidos en Códigos y constituciones (Madrid, 1989).

Al cerrarse el fecundo y prolongado paréntesis de la magistratura constitucional, reingresó Tomás y Valiente en la universidad provisto de un bagaje verdaderamente excepcional, con su vocación académica y su pasión por la Historia intactas, con su formación jurídica enriquecida y depurada por su experiencia jurisdiccional. No tardaría en ser reclamado como consejero de Estado, electivo y, más tarde, permanente. Pero antes de que cristalizara dicho requerimiento retornó a los claustros y reemprendió con normalidad y absoluta entrega sus tareas académicas, profesorales y de estudioso, incrementando con nuevos títulos su abundante producción investigadora.

Mención aparte merece en esta sede su relación con el Anuario en el que escribo. Colaborador temprano y reiterado, como ha quedado dicho, Tomás y Valiente se incorporó a su Consejo de Redacción en 1983. Al transformarse éste en Consejo de Dirección a fines de 1985, continuó perteneciendo ininterrumpidamente al mismo hasta su disolución. A lo largo de estas breves pág1nas he procurado mantener un tono deliberadamente presidido por la sobriedad $y$, por razones que no hace falta explicitar, me he permitido muy escasos juıcios de valor. Sé bien hasta qué punto repugnaba a mi maestro la hagiografía y me he considerado obligado a refrenar mis sentimientos, mis opiniones y, desde luego, a contener la emoción que me produce transitar por la vertiente de su vida que toca a la Historia del Derecho. Mas, llegados a este punto, ruego al lector me conceda licencia para transmitirle ahora siquiera una pálida imagen de la ilusión y el entusiasmo que en Tomás y Valiente despertaba cuanto afectase al Anuario. Sus gravosas obligaciones y sus elevadas responsabilidades en los años ochenta y comenzos de los noventa nunca le impidieron asistir a las reuniones del Consejo de Dirección y cumplir con asombrosa asiduidad, espíritu riguroso, atento e imparcial, las obligaciones a este respecto. En 1993 fue nombrado Dırector de la revista, que él deseaba por encima de todo -como escribiera en la página «Al lector» del volumen LXII- «lugar de encuentro de todos los historıadores del Derecho (españoles o no) y de aquellos historıadores que con sus trabajos y su actitud muestran interés activo por la Historia del Derecho y de las instituciones». Como responsable del Anuario no tardó en introducir meditadas innovaciones que están a la vista de todos, y otros muchos proyectos acariciaba para continuar mejorándolo sin desvirtuar su carácter. 
Carezco de dotes proféticas. Tampoco deseo entrar en el terreno de las suposiciones. Como he escrito en otro lugar, me niego a extraer sonidos de partituras que quedaron inacabadas. Pero no se puede dejar de recordar que, presente en las páginas del Anuario desde 1960, el tomo LXV correspondiente a 1995 cobijó uno de sus últimos trabajos publicados en vida, cuyo título anunciaba que era el primero de una serie que ya no podrá proseguir. Ni esa serie ni tantos otros proyectos, truncados el 14 de febrero de 1996 por una muerte prematura, inicua y absurda, que a quienes el destino nos regaló la oportunidad de tratarle, quererle y admirarle, nos ha dejado irremisiblemente sumidos en el desconsuelo. 